Journal of Psychiatric \& Mental Health Nursing

Volume 8 Page 269 - June 2001

doi:10.1046/j.1365-2850.2001.0401a.x

Volume 8 Issue 3

\title{
Commentary
}

\section{Knowing me knowing you: towards a new relational politics in 21st century mental health nursing}

\author{
Alec Grant
}

\section{Introduction: social constructionism}

'I think we need a new (gulp) paradigm . . . of mental health and what it means to be a nurse. These are highly problematic concepts . . .' (Tony O'Brien, Auckland, NZ, Psychiatric Nursing Mailbase, 2000).

Social constructionism, an interdisciplinary paradigm, has emerged from a crisis in the social sciences in the late 20th century (Gergen 1999). This crisis is around the failure of modernist values to help us understand, and achieve mastery over, the worlds we live around a number of cohering areas. These include 'grand narrative', 'imperialist' claims to the true nature of a supposed external reality (realism) and the true nature of something or someone (essentialism). Not surprisingly, suspicion has been increasingly accorded to related modernist assumptions of selves as rational agents, free to make choices and take direct action on the world. All of this has called into question the notion of individual consciousness as a reliable and adequate mirror of this world, with language as a nonproblematic, neutral and descriptive vehicle of representation.

From a social constructionist perspective, language is constitutive of reality. If language has a performative, action-oriented function (Potter \& Wetherell 1987, Edwards \& Potter 1992, Burr 1995), there is no need to assume a 'real world' separate from or existing prior to its linguistic construction (Burr 1995). The concepts we use in day-to-day interaction do not predate language but are made possible by it (Sapir 1947, Burr 1995). Language emerges as a possible battleground, where constructions of the what is, is not, or should be of life are contested, in a 'site of struggle, conflict and potential personal and social change' (Burr 1995, p. 44).

Berger \& Luckmann (1966) argue that the mechanism governing the genesis and maintenance of the successful social construction of reality is the process of externalization, objectification and internalization; to quote from Burr (1995, p. 10): 
'People "externalise" when they act on their world, creating some artefact or practice ... [for example] . . . by telling a story or writing a book ... this then enters into the social realm, and once in this ... begins to take on a life of its own. The idea that it expresses has become an 'object' of consciousness for the people in that society . . . and has developed a kind of factual existence or truth . . . which appears . . . "natural", issuing from the nature of the world itself rather than dependent upon the constructive work and interactions of human beings . . . they "internalise" it as part of their consciousness . . .'

\section{The social construction of professional identity}

Within the shared project of the social construction of reality, dialoguing communities influence what is or is not done in social practice (Schutz 1980). This in turn reflects what it is or is not legitimate to talk about in the construction of reality. The way society is organized in social structure is achieved by this process, ultimately confirming and reifying what people say and write. By implication, the process involves the production of selfhood (Hall 2000) and in related terms, for the purposes of this paper, professional and organizational identity.

If accepted, the implications of the social construction of identity within organizational life are enormous. I will argue later for a positive implication for mental health nurses of a far greater conscious investment in relational politics. This could have a potential liberating function, in the process of resisting 'either-or' current forms of representation and the production of new constructions of organization and identity. However, for the moment it may be instructive to briefly look at more global, sinister implications. The insidious influence of hierarchical paternalism in meaning construction in the so-called 'developed world' results in managed information, used in the circulation of accounts of (national) identity. What is asserted is less important than what is omitted, resulting in a public arguably 'groomed, rather than brainwashed' (Pilger 1998, p. 448). Pilger convincingly uncovers the process that leads many of us to be blind to the propaganda and censorship of the 'free world', because the exploitation and inhumanity perpetrated in the name of democracy is sanitized out of the journalistic soundbite.

Although at first sight this may seem of little relevance to mental health nursing, we are reminded by Nader (1972) of the value of 'studying up' exploring relationships between micro and macro social phenomena. In this vein, you don't have to be a conspiracy theorist to accept in principle that patriarchal influence serves to socially structure the organizations within which mental health nurses work, in turn influencing their sense of organizational 'reality' and professional identity (Hearn 1993, Putnam \& Mumby 1993, Hearn \& Parkin 1999, Grant 2000). At the organizational symptomatic level, for example, there is good reason to suspect that the emotional, physical and sexual abuse of staff and patients alike in inpatient psychiatric units may be under-reported. If accepted as a reasonable suspicion, this may be because such abuse is inscribed within the social structuring of organizations, and is insufficiently arousing for many staff who have habituated to their own and 
others' distress (Ward 2000). In constructionist theoretical terms, it can be argued that the social process leading to the organization of inpatient treatment emerging as an acceptable arrangement over time creates the potential for abuse in the first place.

\section{Discursive practices, ideology and 'truth'}

The social construction of professional identity is relatively unstable, affected as it is by shifting time and social context. The 'taken for granted' realities of any one occupational group will mutate over the years as a function of the emergence of new discourses inseparable from, and constituting, fields of power. Discourses can be understood as 'practices which form the objects of which they speak' (Foucault 1972, p. 49), in other words grids of meaning through which we interpret and act upon our life-worlds. Discursive practices serve to provide the basis, parameters and boundaries of what can and cannot be spoken about.

It follows that an important moral dimension of discursive practice is in the conferment of value on certain ways of constructing polarized professional world views, with reference to, and at the expense, others - for example, 'my view of mental health nursing is cool and evidence-based whereas yours is sentimental, pink and fluffy'. Dominant discourses, successful by dint of their performative and rhetorical effects, but tacitly claiming to represent 'the truth', as in all other aspects of life, silently 'hail' individuals to accept socially constructed accounts of life, and thus subjective, ideological, positions of one form of professional identity over another (Althusser 2000). Ideology in this context may be understood as 'attempts to simplify, to obscure or erase contradictions, to invert reality, to produce monoliths' (Hearn \& Parkin 1999, p. 148). By this process, constructions of professional identity thrive, wither or vie, one with the other, for a limited time.

With the above theoretical framework in mind, it is useful at this point to critically, selectively and playfully explore some dominant discursive themes in contemporary British mental health nursing. Doing so will facilitate the identification of modernist ideological mechanisms at play in the relatively successful construction of current professional identities.

\section{Barker-Gournayism}

Just as the Berlin wall functioned as a positioning ideological divide for many years, Barker-Gournayism has emerged as two sides of one ideological coin. At first blush, those of us discursively positioned within it may be seen to belong to one of two opposed camps. However, the irony is that neither camp could exist independently, since the totalizing claims of either one both presuppose, and attempt to silence, the claims of the other (Derrida 1980). In so doing, the importance of the other's discursive position is proclaimed. Each camp is forced into what Gergen (1995) describes as an 'identity trap' that serves to confirm the other's sense of moral superiority. 
The meaning of Barker-Gournayism is not in the respective minds of either camp, nor in any kind of 'real world' which predates written or spoken communication, but is embedded within current relational and organizational scenarios (Gergen 1995). In an important sense, specifically because of the strength of the polarizing dialogue which has developed, an arguable effect may be of little apparent space left for alternative constructions of mental health nursing identity in some quarters. Individuals are, by default, forced into a pro or anti position. Either way, the parameters of the dialogue, constructed within the Barker-Gournay symbiosis, remain intact.

In the 'culture war' (Gergen 1995) over the fundamental meaning of mental health nursing the social genesis of either view is effaced, and this strengthens tacit appeals to 'the truth' expressed in polarized terms. Consequently, a military metaphor emerges as appropriate for seeing more or less 'totally sold' individuals engage, rather predictably, in open combat. The battle of words in the 'nurse brutalist debate', for example, revealed the moral basis for the campaign: truth vied with falsehood, empirical respectability with qualitative waffle, defamatory character assassination with assertions of the deliberate use of irony for literary effect, and the Gournay camp's realism was attacked as an identity-trapping language game (Barker 1999, Cannon et al. 1999, Clarke 1999, Duncan-Grant 1999, Ritter 1999, Rogers 1999, Stevenson 1999; Clarke, personal communication)

However, in the dialogic conflict, similarities exist between both camps, which are submerged under what appears to make each radically different from the other. While the content of the world view of each appears opposed, both sides, at worst, are guilty of ideological imperialism in essentializing mental health nursing. The strength of the ideological appeal of either side to 'hail' new subjects rest precisely in seductive language used in the organized construction of nursing identity. Implicit, but questionable, messages given by each camp are around mental health nurses' freedom to make rational choices in the development of professional identity. These may be gift wrapped in either seductive exhortations to transcend to the dizzy spiritual height that is, in a timeless sense, (nontechnical) mental health nursing, or 'get real' in unpretentious, down-to-earth, empirically respectable, transprofessional mental health practice. At worst, inevitably, these messages sanitize, mislead, falsely homogenize, gloss over, and fail to adequately contain and make sense of the difficulties and contradictions nurses will face in living up to the professional subjectivities proposed in either world view. A look at the November 2000 edition of Mental Health Practice, for example, illustrates the postmodern nightmare of contradictory messages that is new millennium inpatient mental health nursing:

'... nurses on some wards are so overstretched they are unable to observe continually all patients who are identified as being at risk of suicide' (p. 3).

'Mental health nurses should not be placed in situations in which their patients' human rights could be infringed' (p. 3). 
And, in relation to the inappropriate use of seclusion:

'It is everyone's responsibility to be vigilant about the use of any restrictive nursing practices and to question our own use of such activities' (p. 9).

As successful social construction, in the sense of achieving desired performative and rhetorical effects, Barker-Gournayism has, for many individuals, for too long served to conceal and marginalize other possibilities. These include broadening the dialogue to encompass different theoretical or conceptual 'takes' on mental health nursing identity or identities, to either supplement or challenge existing representations. Before turning to a tentative outline of some possible ways forward, it is worth considering the possible factors contributing to forms of organizational unwillingness to engage in new discourses of mental health nursing. The following section constitutes an incomplete and imperfect position around this question, but one that has some merit in resonating with the research and work experiences of myself and my colleagues in organizational life.

\section{Resistance}

Many contemporary mental health nurses cling firmly to Barker-Gournayism and other sacred cows, arguably because of the cultural strength of beliefs of rational individuals operating in rational organizations. Gergen (2000) argues that this process may occur because of the strength of world views which, although flawed, are firmly rooted in modernist assumptions which continue to hold sway.

Modernist assumptions of rational individuals and organizations also, of course, inform research dialogues. Gournay et al. (2000), for example, suggest that the reasons for the failure of cognitive behavioural psychotherapy to more significantly influence mental health nursing practice is, in large part, because of the failure of course leaders to convince service managers of its importance. Extremely naïve in organizational change terms, in making this claim these authors are of course falling into the 'myth of the hero innovator' trap. Individuals are set up for inevitable failure when and if charged to influence large-scale changes in the custom and practice of organizations (Georgiades \& Phillimore 1975).

Such claims also reflect the failure of educational and culture change stakeholders to consider the problem of the transfer from curriculum to organizational practice in sufficiently broad socio-cultural terms (Grant and Mills 2000, Tarrier 1999). In spite of current rhetorics of enterprise, where $c$. 1940s organizations aspire to become successful mission statement cultures, bureaucracies arguably sustain socially constructed systems of custom and practice which inhibit and undermine large scale innovation (Pfeffer 1981).

Why should psychiatric/mental health nurses - academic or clinical-be unwilling to critique the organization in the service of constructing new dialogues around professional identity? Broaden-ing the meaning of 
organizations from bricks and mortar to 'in the head' phenomena (Wright 1994), the dominant discursive positions offered by Barker-Gournayism offer us existentially secure 'homes' (Yalom 1980, Fineman 1993). I have already argued above for the operation of organizational homeostasis in the maintenance of organizational custom and practice. To seriously deconstruct this may amount to revisioning the bureaucratic environments that mental health nurses work in as sites of multiple oppression (Hearn \& Parkin 1999). This in turn could trigger off large-scale organizational existential insecurity (Fineman 1993), where the relative meaninglessness (Yalom 1980) of organizational life, and by implication professional identity, would come into sharp focus.

It is indeed scary to reflect on the possibility that, at micro and macro levels, organizations are suspect. In the context of debates on professional identity, it is relatively unusual in mental health nursing dialogues to consider the possibility that organizations discursively socialize individuals to be - at worst - untrustworthy, or to become so inscribed within corporate narratives to forget that organizations could be different. Bureaucratic organizations socialize members to 'forget' that frontstage activity around public impression management, where convenient image-making masquerades as reality, belies much sinister backstage work (Goffman 1969). Supporting the views of Purser \& Cabana (1998), what doesn't appear in the glossy broadsheets or mission statements are the hidden relational dynamics of conflict among functions or departments, power unrelated to knowledge or expertise influencing decisionmaking, a lack of co-operative behaviour between powerful individuals and departments, combined with a reluctance to change or challenge existing practices and procedures.

Not surprisingly, many organizations within which mental health nurses work have problems around learning from experience or learning about learning (Morgan 1997). This makes related, modernist-based discourses on 'selfawareness' and 'reflective practice', both of which currently enjoy a cosy relationship with mental health nursing identity, seem like so much facile rhetoric. By implication, at both corporate and individual levels, serious reflection around professional identity of the type suggested by social (de)constructionist principles may be immensely threatening to Trusts and to mental health nurses equally.

\section{An outline of possible ways forward}

I have argued that meaning is embedded within relational scenarios and that, as a vehicle for making meaning, 'language is shaped neither by nature nor mind, but by (organised) relationship' (Gergen 1995, p. 7). I have further argued that in a reciprocal and dynamic way, written or spoken dialogue informs both social process and social structure. What then are the implications for the possible development of new forms of dialogue, social process and structure within mental health nursing?

Broadly, the charge is for generic and specialist nurses to develop more critical theoretical positions within a new and emerging relational politics 
(Gergen 1995). It is timely for nurses to revision themselves in their writing and talking in ways that take account of sadly neglected factors influencing professional identity. Attaining critical repertoires will enable nurses to challenge current polarizing constructions around what is good/bad or right/wrong in contemporary mental health nursing practice, and to explore the relationship between micro- and macro-organizational influences on identity construction. Greater sensitization to the pragmatics of language will undermine notions of benign organizations and subject both those organizations and the conceptual, strategic and research rhetorics underpinning them to moral and political debate.

More specifically, it may be timely for mental health nurses to develop incorporative, unifying, rather than either-or dialogues, where the sense in which our identities are 'constituted by and with others' (Gergen 1995, p. 10) is sympathetically acknowledged. We need to develop conversational resources that suspend the rhetoric of individual or group blame. By this means we could amicably explore common concerns, using conference devices such as taking the role of the other in playfully and respectfully engaging in each other's self-doubts and fears (Gergen 1995). Without implying a need for any kind of 'wooly eclecticism', doing so may help us develop more of a professional sense of ourselves as 'multiple-partials' (Gergen 1995, p. 11). It is indeed possible to be simultaneously inspired and moved by Barker's writing while respecting the significant contributions of Gournay, without being trapped in an either-or language game. A relational politics which is both diffused and defused - expanded into all corners of professional life and reduced in its aggressive, alienating posture-would move the sense of politics into the local and immediate through new forms spoken and written dialogue (Rolfe 2000).

It may be helpful at this point to illustrate the relevance of the above suggestions with some specific and current examples of inertia problems in organized dialogue. In the psychiatric nursing mailbase, there seems good evidence to suggest that some individuals fear to engage in heated debates with thick-skinned contributors (Auld, personal communication). Those that do risk the possibility of anonymous abusive e-mails from some members if the current, unspoken and tacitly policed, discursive rules are broken (Fineman 1993; Simpson, personal communication).

At the terrestrial level of macro-organizational life, dominance of institutional monololiths is illustrated by two further examples, from nurse education and research, respectively. In generic mental health nurse education, the last vestiges of the 'monologic voice of authority' in the classroom or 'one right answer' approach need to be abandoned in favour of inviting students to consider and challenge the received opinions of authorities in the field - to effectively learn how to think critically. The risk for some stakeholders is that this may, inevitably, signal the death knell of humanism and the lone, reflective, rational agent aspiring to an imagined self-awareness, shifting the agenda to a much needed focus on forms of relationship in constructing meaning and identity. 
'Specialist' 'nurse' cognitive behavioural psychotherapy practitioners can and should challenge the research following up ENB 650 trained nurses. Despite the appearance of 'neutral' research, the combination of design choice and thinly disguised ideological commitment displayed in Gournay et al. (2000) paints a contestable picture of an homogenous advanced practitioner - the so called 'nurse behaviour therapist'. It has to be said that the Institute of Psychiatry ENB 650 course has broadened its curriculum in recent times to include more of an emphasis on the therapeutic relationship, cognitive case formulation, and a concern about the potential for organizational factors to negatively impact on practitioners. However, in spite of this, insufficient attention has been paid by Gournay and colleagues to the possibility that not all ENB 650 graduates accept the narrow client range, diagnostically led, form of behavioural-cognitive therapy expounded in past years by the London course. In the same vein, little attention is apparent in this research to the possibility that so-called 'nurse therapists' may inevitably develop in terms of incorporating different psychotherapeutic and sociocultural world views in their experiential and practice repertoire (Duncan-Grant 1999, Barker 2000; Tilley, personal communication). Similarities rather than differences are thus inevitably constructed within a, until recently, dominant 'party line' version of behavioural-cognitive nursing training and practice favoured at the Institute of Psychiatry, and the wisdom of deviance from this line is called into question.

\section{To end at the beginning}

We may be on the cusp of creating new possibilities for organizing our identities through dialogue. New organizations can develop, resistance to 'forced' identities made explicit (hooks 1994), and hybrid forms nurtured and encouraged. To paraphrase George Kelly, psychiatric/mental health nurses need no longer be the victims of their (constructed) biographies. Morgan (1997) similarly reminds us that organizations (virtual, bricks and mortar, in the head, and culture war) within which mental health nurses currently find themselves inscribed, need to be exposed as 'psychic prisons'. No longer should we allow potential messages of identity change to decay, or be sabotaged in the cycle of current exchange that serves to maintain the status quo of organizational practice and safety

\section{References}

- Althusser L. (2000) Ideology interpellates individuals as subjects. In: Identity: A Reader (eds Gay P., Evans J. \& Redman P.), pp. 31-38. Sage, London, in association with The Open University, Milton Keynes.

- Barker P. (1999) Arrested development. Mental Health Care 21, 393.

- Barker P. (2000) The Ripples of Knowledge and the Boundaries of Practice: the Problem of Evidence in Psychotherapy Research. Keynote address to the European Association of Psychotherapy Congress, 'Tradition and Transition'. University College, Dublin, Eire 25 June 2000.

- Berger P. \& Luckmann T. (1966) The Social Construction of Reality: A 
Treatise in the Sociology of Knowledge. Doubleday, New York.

- Burr V. (1995) An Introduction to Social Constructionism. Routledge, London.

- Cannon B., Coulter E., Gamble C., Jackson A., Jones J., Sandford T., Sharkey S., Ward M., West L. (1999) Personality bashing. Mental Health Care 21, 319.

- Clarke L. (1999) Nursing in search of a science: the rise and rise of the new nurse brutalism. Mental Health Care 21, 270-272.

- Derrida J. (1980) Of Grammatology, 4th edn. (trans. Spivak G.C.). Johns Hopkins University Press, Baltimore.

- Duncan-Grant A. (1999) Misrepresentation, stereotyping, and acknowledging bias in science: responses to Liam Clarke. Mental Health Care 21, 336-337.

- Edwards D. \& Potter J. (1992) Discursive Psychology. Sage, London.

- Fineman S., ed. 1993) Emotion in Organisations.. Sage, London.

- Foucault M. (1972) The Archaeology of Knowledge. Tavistock, London.

- Georgiades N.J. \& Phillimore L. (1975) The myth of the hero-innovator and alternative strategies for organisational change. In: Behavioural Modification with the Severely Retarded (eds Kiernan C.C. \& Woodford F.P.). Associated Scientific Publishers, London.

- Gergen K. (1995) Social Construction and the Transformation of Identity Politics. http://www.swarthmore.edu/SocSci/kgergen1/text8.html.

- Gergen K.J. (1999) An Invitation to Social Construction. Sage, London.

- Gergen K. (2000) Organizational science in a Postmodern Context. http://swarthmore.edu/SocSci/kgergen1/text10.html.

- Goffman E. (1969) The Presentation of Self in Everyday Life. Pelican Books, Reading.

- Gournay K., Denford L., Parr A.-M., Newell R. (2000) British nurses in behavioural psychotherapy: a 25 year follow-up. Journal of Advanced Nursing 32, 343-351. 
Grant A. (2000) Clinical supervision and organisational power: a qualitative study. Mental Health and Learning Disabilities Care 31, 398-401.

- Grant A. \& Mills J. (2000) The Great Going Nowhere Show: Structural power and mental health nurses. Mental Health Practice 4, 6-7.

- Hall S. (2000) Who needs 'identity'?. In: Identity: A Reader (eds Gay P., Evans J. \& Redman P.), pp. 15-30. Sage, London, in association with The Open University, Milton Keynes.

- Hearn J. (1993) Emotive subjects: organisational men, organisational masculinities and the (de)construction of 'emotions'. In: Emotion in Organizations (ed. Fineman S.), pp. 142-166. Sage, London.

- Hearn J. \& Parkin W. (1999) Organizations, multiple oppressions and postmodernism. In: Postmodernism and Organizations (ed Hassard J. \& Parker M.), pp. 148-162. Sage, London.

- hooks B. (1994) Outlaw Culture: Resisting Representations. Routledge, London.

- Morgan G. (1997) Images of Organisation, 2nd edn. Sage, Thousand Oaks.

- Nader L. (1972) Up the anthropologist: perspectives gained from studying up. In: Reinventing Anthropology (ed. Hymes D.), pp. 123-130. Random House, New York.

- Pfeffer J. (1981) Power in Organizations. Pitman, Marshfield.

- Pilger J. (1998) Hidden Agendas. Vintage, London.

- Potter J. \& Wetherell M. (1987) Discourse and Social Psychology: Beyond Attitudes and Behaviour. Sage, London.

- Purser R.E. \& Cabana S. (1998) The Self-Managing Organisation: How Leading Companies Are Transforming the Work of Teams for Real Impact. Simon and Shuster, New York.

- Putnam L.L. \& Mumby D.K. (1993) Organizations, emotion and the myth of rationality. In: Emotion in Organizations (ed Fineman S.), pp. 36-57. Sage, London.

- Ritter S. (1999) Insulting distortion. Mental Health Care 21, 319. 
- Rogers P. (1999) Persecution complex. Mental Health Care 21, 319.

- Rolfe G. (2000) Write! Now! Journal of Psychiatric and Mental Health Nursing 7, 468-470

Sapir E. (1947) Selected Writings in Language, Culture and Personality. University of California Press, Los Angeles.

- Schutz A. (1980) The Phenomenology of the Social World. (trans. Walsh G. \& Lehnert F.). Heinemann, London.

- Stevenson C. (1999) Power and control. Mental Health Care 21, 393.

- Tarrier N. (1999) The dissemination of innovative cognitive-behavioural psychosocial treatments for schizophrenia. Journal of Mental Health 8 , 569-582.

Ward M. (2000) Seclusion or exclusion. Mental Health Practice 4, 6-7.

- Wright S. (1994) Culture in anthropology and organisational studies. In: Anthropology of Organizations (ed Wright S.), pp. 9-31. Routledge, London.

- Yalom I.D. (1980) Existential Psychotherapy. Basic Books, New York. 